\title{
Infrared Absorption Spectra of Cyclo-Hydrocarbons
}

\author{
By Earle K. Plyler and Nicolo Acquista
}

\begin{abstract}
The infrared absorption spectra of 19 hydrocarbons have been measured in the 3.4micron region, and the location of the two $\mathrm{CH}_{2}$ vibrations has been determined. The vibrations occur at 2,854 and $2,927 \mathrm{~cm}^{-1}$ for the methylcyclohexane and 2,866 and 2,952 $\mathrm{cm}^{-1}$ for the methylcyclopentane. For cyclohexene the wave numbers of the bands are 2,845 and $2,934 \mathrm{~cm}^{-1}$, and for cyclopentene they occur at 2,853 and $2,959 \mathrm{~cm}^{-1}$.

The region from 2 to 4 microns has been measured for methylcyclohexane, ethylcyclohexane, cis-1,2-dimethylcyclohexane, trans-1,2-dimethylcyclohexane, and the corresponding cyclopentanes. Also, the spectra of cyclohexene and cyclopentene have been measured from 2 to 4 microns. The near infrared bands of methylcyclohexane, methylcyclopentane, and ethylcyclopentane have been classified as fundamentals and as combinations of long wavelength bands.
\end{abstract}

\section{Introduction}

The infrared absorption spectra of hydrocarbons have been measured for the purpose of identification by means of characteristic bands. Also, such data are useful as a measure of the purity of compounds. There have been some investigations in narrow regions of the spectrum, for example from 1 to $2 \mu$, to see if the differences in the spectra of various types of hydrocarbons were sufficient for identification. Liddel and Kasper $[1]^{1}$ were able to show certain changes in the spectra of groups such as the aromatic and aliphatic compounds in the regions of 1.1 and $1.7 \mu$. They found that primary, secondary, and tertiary linkages seemed to change the position of certain bands. There was some indication in their studies that the manner in which the $\mathrm{CH}_{2}$ and $\mathrm{CH}_{3}$ groups were arranged could be ascertained from the spectra. Rose [2] measured the absorption of 19 hydrocarbons in the near infrared, 9 of low molecular weight $\left(\mathrm{C}_{8}\right.$ to $\left.\mathrm{C}_{10}\right)$ and 10 of high molecular weight $\left(\mathrm{C}_{24}\right.$ to $\mathrm{C}_{32}$ ). It was assumed by Rose that each $\mathrm{CH}$, $\mathrm{CH}_{2}$, and $\mathrm{CH}_{3}$ group in the molecule would make a fixed contribution to the absorption in a band. By measuring the amount of absorption for a

${ }_{1}^{1}$ Figures in brackets indicate the literature references at the end of this paper. given hydrocarbon, the number of groups in each configuration could be determined. Experimentally he found that isomers did not have the same amount of absorption in the $1.7-\mu$ region and that the assumption was not valid. Although the absorption of the $1.7-\mu$ band, which is the harmonic of the $\mathrm{CH}$ stretching vibration at $3.4 \mu$, may roughly be considered independent of the molecule as a whole, the position and intensity of this band is somewhat influenced by the structure of the entire molecule.

Fox and Martin [3] investigated the absorption of several hydrocarbons in the region of the $3.4 \mu$. They were interested in the absorption of the $\mathrm{CH}_{2}$ groups in different types of molecules such as benzyl alcohol, dioxane, and cyclohexane. The results showed that the $\mathrm{CH}_{2}$ groups usually give rise to two bands in the $3.4-\mu$ region and the $\mathrm{CH}$ groups produce one band. However, in some molecules, for example dioxane, there was an interaction between groups that gave rise to several bands. Fox and Martin also studied ethylene and showed that the $\mathrm{CH}_{2}$ groups in that molecule had absorption bands in the $3.4-\mu$ region that were similar to the bands of the larger molecules containing $\mathrm{CH}_{2}$ groups. In molecules that have only $\mathrm{CH}_{2}$ groups, the two bands were produced by the $\mathrm{CH}$ valence vibration with the hydrogens in and 
out of phase. In cyclohexane, which has several $\mathrm{CH}_{2}$ groups, the number of bands observed at $3.4 \mu$ may be greater than two on account of interactions between the groups. The way in which the $\mathrm{CH}_{2}$ group is linked in the molecule may produce changes in the location of the band. However, the mass of the other part of the molecule has small effect on the position of the two bands of the group. Molecules, which are not hydrocarbons but contain the $\mathrm{CH}_{2}$ group, also have two bands in 3.4- $\mu$ region. The formaldehyde molecule has vibrations with smaller wave numbers than those found for $\mathrm{CH}_{2}$ groups in hydrocarbons, but in fluorene, $\left(\mathrm{C}_{13} \mathrm{H}_{10}\right)$, the wave numbers for the $\mathrm{CH}_{2}$ groups are larger. This indicates that the binding forces in neighboring groups of the molecules have some effect on the vibrations observed in the $3.4-\mu$ region.

The results that have just been described do not take into consideration the contribution of harmonic and overtone bands in the region of $3.4 \mu$. By measuring the region from 2 to $4.5 \mu$ with good resolution, many bands of low intensity may be observed. The spectrum in this region may be sufficient for identification of the hydrocarbon, because some of the overtone bands will include the long wavelength bands that are commonly used for distinguishing one hydrocarbon from another.

The present investigation is primarily concerned with the absorption spectra of some cyclopentanes and cyclohexanes in the 3.4- $\mu$ region. The spectra of cyclopentene, cyclohexene, and some benzene derivatives have been measured for comparison with the other hydrocarbons. Two isomers, cis1,2-dimethylcyclohexane and trans-1,2-dimethylcyclohexane have been studied in the region from 2 to $4 \mu$.

\section{Experimental Results}

A Perkin-Elmer infrared spectrometer with an $\mathrm{LiF}$ prism was used for the resolving instrument. All the substances measured were standard samples of the National Bureau of Standards. Two cells, 0.05 and $0.2 \mathrm{~mm}$ in thickness, were used for measuring the liquids. For the region of $3.4 \mu$, the hydrocarbons were diluted in $\mathrm{CCl}_{4}$ so that an equivalent cell thickness of $0.0017 \mathrm{~mm}$ was obtained. Preliminary experiments showed that this was a suitable thickness of the material for resolving the main components of the band. It was also of importance to check whether any changes were brought about by the measurement of the hydrocarbons in solution rather than in the pure state. In order to make this comparison a small amount of the liquid was put in a cell, and then the cell was tipped so that the liquid formed a film over the inside surfaces of the cell. As the cell was of the closed type, the film did not evaporate rapidly, and the region from 3.3 to $3.6 \mu$ could be measured under fairly constant conditions. The cell was only $0.05 \mathrm{~mm}$ in thickness, and the saturated vapor would contribute very little to the total absorption.

In figure 1, a is shown the absorption bands of diluted methylcyclohexane and in figure $1, \mathrm{~b}$ the absorption bands of a film of liquid methylcyclohexane. The comparison of a film of the liquid with a dilute solution of the same substance was made for several compounds. It was found that the wavelengths of the two major compounds checked in the two cases to better than $0.01 \mu$.

The spectra of methylcyclohexane and ethylcyclohexane are shown in figure 2 . The two main components of the band at 3.415 and $3.508 \mu$ check closely in position for these compounds, but there is a difference in intensity. The region from 2.5 to $2.85 \mu$ is represented by a broken line. On account of the water vapor in the air path and an absorption band in the prism at $2.78 \mu$, bands of low intensity could not be accurately measured in this region. The presence of the methyl group in one molecule and the ethyl group in the other molecule produces changes in the spectra of the 2 - to $4-\mu$ region. This makes it possible to readily distinguish these two compounds from each other. The wavelengths of the observed bands are given in table 1 .

TABLE 1. Location of infrared absorption bands in the region from 2.2 to 4.2 microns

\begin{tabular}{|c|c|c|c|}
\hline Wavelength & $\begin{array}{l}\text { Wave num- } \\
\text { ber }\end{array}$ & Wavelength & $\begin{array}{c}\text { Wave num- } \\
\text { ber }\end{array}$ \\
\hline \multicolumn{4}{|c|}{ Methylcyclopentane } \\
\hline$\mu$ & $\mathrm{cm}^{-1}$ & $\mu$ & $\mathrm{cm}^{-1}$ \\
\hline 2. 287 & 4,373 & a 3.387 & 2,952 \\
\hline 2. 305 & 4,338 & a 3.489 & 2,866 \\
\hline 2. 327 & 4,297 & 3.663 & 2,730 \\
\hline 2. 416 & 4,139 & 3.707 & 2,698 \\
\hline 2. 454 & 4,075 & 3.807 & 2,627 \\
\hline 3.060 & 3,268 & 3.857 & 2,593 \\
\hline 3.140 & 3,185 & 4.070 & 2,457 \\
\hline
\end{tabular}

Journal of Research 
TABLE 1. Location of infrared absorption bands in the region from 2.2 to 4.2 microns-Continued

\begin{tabular}{|c|c|c|c|}
\hline Wavelength & $\begin{array}{c}\text { Wave num- } \\
\text { ber }\end{array}$ & Wavelength & $\begin{array}{l}\text { Wave num- } \\
\text { ber }\end{array}$ \\
\hline \multicolumn{4}{|c|}{ Ethylcyclopentane } \\
\hline$\mu$ & $\mathrm{cm}^{-1}$ & $\mu$ & $\mathrm{cm}^{-1}$ \\
\hline 2. 292 & 4,363 & a 3.383 & 2,956 \\
\hline 2. 331 & 4,290 & a 3.489 & 2,866 \\
\hline 2.422 & 4,129 & 3. 655 & 2,736 \\
\hline 2.456 & 4,072 & 3.778 & 2,647 \\
\hline 3.000 & 3,333 & 3.816 & 2,621 \\
\hline 3.158 & 3,167 & 4. 038 & 2,476 \\
\hline \multicolumn{4}{|c|}{ cis-1,2-Dimethylcyclopentane } \\
\hline 2. 268 & 4,409 & a 3.487 & 2,868 \\
\hline 2. 297 & 4,354 & 3. 655 & 2,736 \\
\hline 2.317 & 4,316 & 3. 678 & 2,719 \\
\hline 2.397 & 4,172 & 3. 725 & 2,685 \\
\hline 2.451 & 4,080 & 3.768 & 2,654 \\
\hline 3.031 & 3,299 & 3.814 & 2,622 \\
\hline 3.143 & 3,182 & 3.853 & 2,595 \\
\hline a 3.382 & 2,957 & 4. 032 & 2,480 \\
\hline - n & (n) & 4. 132 & 2,420 \\
\hline \multicolumn{4}{|c|}{ Cyclopentene } \\
\hline 2. 284 & 4,380 & a 3.450 & 2,903 \\
\hline 2. 322 & 4,306 & a 3.505 & 2,853 \\
\hline 3. 031 & 3,299 & 3.615 & 2,766 \\
\hline 3.096 & 3,229 & 3.665 & 2,728 \\
\hline a 3.260 & 3,067 & 3. 795 & 2,635 \\
\hline a 3.380 & 2,959 & 3. 895 & 2,567 \\
\hline a 3.415 & 2,928 & - & - \\
\hline \multicolumn{4}{|c|}{ trans-1,2-Dimethylcyclopentane } \\
\hline 2. 268 & 4,409 & a 3.145 & 3,180 \\
\hline 2. 303 & 4,342 & a 3.387 & 2,952 \\
\hline 2. 326 & 4,299 & 3. 489 & 2,866 \\
\hline 2.346 & 4,263 & 3. 617 & 2,765 \\
\hline 2. 397 & 4,172 & 3. 664 & 2,729 \\
\hline 2.454 & 4,075 & 3.704 & 2,700 \\
\hline 2.486 & 4,023 & 3.805 & 2,628 \\
\hline 3.006 & 3,327 & 3.873 & 2,582 \\
\hline 3.039 & 3,291 & 4. 078 & 2,452 \\
\hline (n......... & - n........ & 4. 156 & 2,406 \\
\hline \multicolumn{4}{|c|}{ Methylcyclohexane } \\
\hline 2. 300 & 4,348 & a 3.504 & 2,854 \\
\hline 2. 337 & 4,279 & 3.579 & 2,794 \\
\hline 2.390 & 4,184 & 3. 669 & 2,726 \\
\hline 2.422 & 4,129 & 3. 696 & 2,706 \\
\hline 2.454 & 4,075 & 3.751 & 2,667 \\
\hline 2. 483 & 4,027 & 3.778 & 2,647 \\
\hline 2. 887 & 3,464 & 3,839 & 2,605 \\
\hline 2. 987 & 3,348 & 3. 889 & 2,571 \\
\hline 3.057 & 3,271 & 3.920 & 2,551 \\
\hline 3.078 & 3,249 & 3,986 & 2,509 \\
\hline 3. 162 & 3,163 & 4. 027 & 2,483 \\
\hline 3.240 & 3,085 & 4. 054 & 2,468 \\
\hline a 3.416 & 2,927 & 4. 122 & 2,426 \\
\hline (n-non & - n & 4. 170 & 2,398 \\
\hline
\end{tabular}

TABLE 1. Location of infrared absorption bands in the region from 2.2 to 4.2 microns - Continued

\begin{tabular}{|c|c|c|c|}
\hline Wavelength & $\begin{array}{l}\text { Wave num- } \\
\text { ber }\end{array}$ & Wavelength & $\begin{array}{c}\text { Wave num- } \\
\text { ber }\end{array}$ \\
\hline \multicolumn{4}{|c|}{ Ethylcyclohexane } \\
\hline$\mu$ & $\mathrm{cm}^{-1}$ & $\mu$ & $\mathrm{cm}^{-1}$ \\
\hline 2. 300 & 4,348 & a 3.420 & 2,924 \\
\hline 2.341 & 4,272 & a 3.482 & 2,872 \\
\hline 2. 394 & 4,177 & a 3.509 & 2,850 \\
\hline 2.426 & 4,122 & 3. 668 & 2,726 \\
\hline 2. 443 & 4,093 & 3. 746 & 2,670 \\
\hline 2.486 & 4,023 & 3. 839 & 2,605 \\
\hline 2. 895 & 3,454 & 3.880 & 2,577 \\
\hline 2. 949 & 3,391 & 3. 940 & 2,538 \\
\hline 2. 979 & 3,357 & 4. 029 & 2,482 \\
\hline a 3.170 & 3,155 & 4. 126 & 2,424 \\
\hline a 3.575 & 2,667 & 4. 174 & 2,396 \\
\hline a 3.377 & 2,961 & (n) & - n \\
\hline \multicolumn{4}{|c|}{ Cyclohexene } \\
\hline 2.300 & 4,348 & a 3.500 & 2,857 \\
\hline 2.317 & 4,316 & a 3.515 & 2,845 \\
\hline 2. 334 & 4,284 & 3. 595 & 2,782 \\
\hline 2. 381 & 4,199 & 3. 635 & 2,751 \\
\hline 2. 422 & 4,128 & 3. 657 & 2,734 \\
\hline 2. 486 & 4,023 & 3. 680 & 2,717 \\
\hline 2. 527 & 3,957 & 3. 720 & 2,688 \\
\hline 2. 952 & 3,388 & 3. 751 & 2,665 \\
\hline 3.021 & 3,310 & 3. 778 & 2,647 \\
\hline 3. 109 & 3,216 & 3.819 & 2,619 \\
\hline 3. 258 & 3,069 & 3.873 & 2,581 \\
\hline a 3.295 & 3,035 & 3. 946 & 2,534 \\
\hline a 3.408 & 2,934 & 3. 978 & 2,514 \\
\hline a 3.452 & 2,897 & 4. 034 & 2,478 \\
\hline \multicolumn{4}{|c|}{ cis-1,2-Dimethylcyclohexane } \\
\hline 2. 268 & 4,409 & 3. 639 & 2,748 \\
\hline 2. 298 & 4,352 & 3. 667 & 2,727 \\
\hline 2. 336 & 4,281 & 3. 714 & 2,693 \\
\hline 2.390 & 4,184 & 3. 753 & 2,665 \\
\hline 2.445 & 4,090 & 3. 839 & 2,605 \\
\hline 2.480 & 4,032 & 3,845 & 2,601 \\
\hline 3.034 & 3,296 & 3. 907 & 2,560 \\
\hline 3.083 & 3,244 & 3. 944 & 2,535 \\
\hline a 3.380 & 2,959 & 3. 995 & 2,503 \\
\hline a 3.418 & 2,926 & 4. 048 & 2,470 \\
\hline a 3.485 & 2,869 & 4. 107 & 2,435 \\
\hline a 3.504 & 2,854 & -nen & - n \\
\hline \multicolumn{4}{|c|}{ trans-1,2-Dimethylcyclohexane } \\
\hline 2.294 & 4,359 & 3. 632 & 2,753 \\
\hline 2. 337 & 4,279 & 3. 649 & 2,740 \\
\hline 2.387 & 4,189 & 3. 663 & 2,730 \\
\hline 2.406 & 4,156 & 3. 684 & 2,714 \\
\hline 2.429 & 4,117 & 3. 702 & 2,701 \\
\hline 2.453 & 4,077 & 3. 738 & 2,675 \\
\hline 2.477 & 4,037 & 3.803 & 2,630 \\
\hline 2.874 & 3,479 & 3,839 & 2,605 \\
\hline 2. 963 & 3,375 & 3. 851 & 2,597 \\
\hline 3.075 & 3,252 & 3. 907 & 2,560 \\
\hline 3. 160 & 3.165 & 3.957 & 2,527 \\
\hline 3. 203 & 3,122 & 3. 977 & 2,514 \\
\hline a 3.387 & 2,952 & 4. 062 & 2,462 \\
\hline a 3.422 & 2,922 & 4. 138 & 2,417 \\
\hline a 3.486 & 2,869 & 4. 170 & 2,398 \\
\hline a 3.506 & 2.852 & - & - \\
\hline
\end{tabular}

: Values determined from observation in $\mathrm{CCl}_{4}$. 
In figure 3 the spectra of two isomers, cis1,2-dimethylcyclohexane and trans-1,2-dimethylcyclohexane are shown. The spectral region from 3.0 to $4.2 \mu$ is sufficient to show differences in the combination bands of these materials. However, the spectra from 3.35 to $3.55 \mu$, curve a, are almost alike. These compounds have been measured [4] with a rock-salt prism from 2 to $15 \mu$, and several of the bands in the 7 - to $15-\mu$ region may be used for identification. With the lower resolution of the rock-salt prism in the $3-\mu$ region, many of the low intensity bands are not observed. The results obtained with an LiF prism are more accurate in near infrared region.

In figure 4 the comparison of the spectra of methylcyclopentane and ethylcyclopentane is shown. The two $\mathrm{CH}_{2}$ vibrations are well defined at 3.38 and $3.49 \mu$, and the vibration with greater wave number has a greater intensity. The two insert curves, a, from the two compounds are similar. The $\mathrm{CH}_{2}$ vibrations in the cyclopentanes are located at shorter wavelengths than are observed in the cyclohexanes. The change in wavelength, about $0.03 \mu$, is sufficient to distinguish between these groups of compounds. The general pattern of the spectra from 2 to 4.2 $\mu$ is the same for methylcyclopentane and ethylcyclopentane, but a difference in the position of the small bands can be observed. The list of the bands observed for these two compounds is given in table 1.

The spectra of cis-1,2-dimethylcyclopentane and trans-1,2-dimethylcyclopentane are shown in figure 5. The spectra of the two dimethylcyclopentanes are different from each other and from the methylcyclopentane. The two $\mathrm{CH}_{2}$ bands in the region of $3.4 \mu$ overlap the two stretching vibrations of the methyl groups, and these bands cannot be resolved as was done in the spectra of the methylcyclohexanes. The two $\mathrm{CH}_{2}$ vibrations have wave numbers of 2,957 and 2,868 $\mathrm{cm}^{-1}$ for the cis compound, and 2,952 and 2,866 $\mathrm{cm}^{-1}$ for the trans compound. The locations of the bands in the 2 - to $4-\mu$ region are listed in table 1.

In figure 6 the spectra are shown of cyclohexene and cyclopentene. The absorption bands are listed in table 1. These molecules have one CC double bond and two $\mathrm{CH}$ groups. The $\mathrm{CH}$ vibrations produce the strong band at $3.26 \mu$ in the spectrum of cyclopentene. In figure 7 the $3.4-\mu$ region is shown in greater detail, and the $\mathrm{CH}$ vibration for cyclohexene falls at $3.30 \mu$. The $\mathrm{CH}_{2}$ vibrations of cyclohexene occur at longer wavelengths than the vibrations of cyclopentene. Cyclohexene vapor shows intense bands at 3.42 and $3.52 \mu$. These values correspond closely with the wavelengths observed for the solution. Almost all of the bands observed in the vapor have $P, Q$, and $R$ branches, and with low resolution it is difficult to determine the center of the band.

In figure 8 a comparison is made of the absorption spectra of methylcyclopentane, trans-1,2dimethylcyclopentane, and cis, cis, trans-1,2,4trimethylcyclopentane. The two main bands at 3.385 and $3.49 \mu$ occur nearly in the same position for the three compounds, but the small bands between these two become more pronounced as the number of methyl groups increases.

In figure 9 the observations for the 3.4- $\mu$ region are represented for eight hydrocarbons. The spectrum of isopropylcyclopentane does not show the small bands that are present in isopropylcyclohexane. This is caused by the overlapping of the $\mathrm{CH}_{2}$ bands, which occur at shorter wavelengths in cyclopentanes. The other six hydrocarbons show the contrast between benzene

TABLE 2. Location of infrared absorption bands in the region from 3.2 to 3.6 microns

(Values determined from observations in $\mathrm{CCl}_{4}$ )

\begin{tabular}{|c|c|c|c|c|c|}
\hline $\begin{array}{l}\text { Wave- } \\
\text { length }\end{array}$ & $\begin{array}{l}\text { Wave } \\
\text { number }\end{array}$ & $\begin{array}{l}\text { Wave- } \\
\text { length }\end{array}$ & $\begin{array}{c}\text { Wave } \\
\text { number }\end{array}$ & $\begin{array}{l}\text { Wave- } \\
\text { length }\end{array}$ & $\begin{array}{l}\text { Wave } \\
\text { number }\end{array}$ \\
\hline \multicolumn{2}{|c|}{ Isopropylcyclopentane } & \multicolumn{2}{|c|}{$n$-Butylcyclohexane } & \multicolumn{2}{|c|}{ ter-Butylbenzene } \\
\hline \multirow{4}{*}{$\begin{array}{c}\mu \\
3.387 \\
3.490\end{array}$} & $\mathrm{~cm}^{-1}$ & $\mu$ & $\mathrm{cm}^{-1}$ & \multirow{6}{*}{$\begin{array}{c}\boldsymbol{\mu} \\
3.265 \\
3.303 \\
3.374 \\
3.411 \\
3.495\end{array}$} & \multirow{6}{*}{$\begin{array}{l}\mathrm{cm}^{-1} \\
3,063 \\
3,028 \\
2,964 \\
2,932 \\
2,861\end{array}$} \\
\hline & 2,952 & 3.384 & 2,955 & & \\
\hline & 2,865 & 3.423 & 2,921 & & \\
\hline & & 3.488 & 2,867 & & \\
\hline \multicolumn{2}{|c|}{ Isopropylcyclohexane } & 3.509 & 2,850 & & \\
\hline \multirow{6}{*}{$\begin{array}{l}3.384 \\
3.422 \\
3.456 \\
3.510\end{array}$} & \multirow{6}{*}{$\begin{array}{l}2,955 \\
2,922 \\
2,894 \\
2,849\end{array}$} & \multirow{2}{*}{\multicolumn{2}{|c|}{ sec-Butylbenzene }} & & \\
\hline & & & & \multirow{2}{*}{\multicolumn{2}{|c|}{ ter-Butylcyclohexane }} \\
\hline & & \multirow{5}{*}{$\begin{array}{l}3.302 \\
3.376 \\
3.418 \\
3.484\end{array}$} & \multirow{5}{*}{$\begin{array}{l}3,028 \\
2,962 \\
2,926 \\
2,870\end{array}$} & & \\
\hline & & & & \multirow{4}{*}{$\begin{array}{l}3.412 \\
3.510\end{array}$} & \multirow{4}{*}{$\begin{array}{l}2,931 \\
2,849\end{array}$} \\
\hline & & & & & \\
\hline & & & & & \\
\hline \multicolumn{2}{|c|}{$n$-Butylbenzene } & & & & \\
\hline \multirow{2}{*}{$\begin{array}{l}\text { 3. } 242 \\
\text { 3. } 264\end{array}$} & \multirow{2}{*}{$\begin{array}{l}3,084 \\
3,064\end{array}$} & \multicolumn{2}{|c|}{ sec-Butylcyclohexane } & \multirow{2}{*}{\multicolumn{2}{|c|}{$\begin{array}{c}\text { cis-cis-trans-1,2,4- } \\
\text { Trimethylcyclo- } \\
\text { pentane }\end{array}$}} \\
\hline & & \multirow[b]{2}{*}{ 3. 378} & \multirow[b]{2}{*}{2,960} & & \\
\hline 3.304 & 3,027 & & & \multirow[b]{2}{*}{3.386} & \multirow[b]{2}{*}{2,953} \\
\hline 3.382 & 2,957 & 3. 419 & 2,925 & & \\
\hline 3.416 & 2,927 & 3.484 & 2,870 & 3.418 & 2,926 \\
\hline 3.488 & 2,868 & 3.508 & 2.851 & 3,450 & 2,899 \\
\hline 3.503 & 2,855 & & & 3. 489 & 2,866 \\
\hline
\end{tabular}


derivatives and cyclohexane derivatives. The three cyclohexanes, $n$-butyl, sec-butyl, and tertbutyl are much alike in their spectra. The three butyl benzenes show marked contrasts in their spectra. The benzenes are less absorbing in this region than the cyclohexanes, and it is possible to see the effect of the butyl compounds more readily. The band at $3.30 \mu$ is characteristic of the $\mathrm{CH}$ vibration and does not appear in the cyclohexane derivatives. The positions of these bands are listed in table 2 .

\section{Discussion of Results}

The experimental results that have been obtained show that the wavelengths of the two $\mathrm{CH}_{2}$ stretching vibrations are influenced by the type of the molecule in which they are included. For example, in methylcyclohexane the two bands are located with wave numbers 2,854 and 2,927 $\mathrm{cm}^{-1}$, whereas the corresponding bands for methylcyclopentane have values 2,866 and $2,952 \mathrm{~cm}^{-1}$.

These changes in the positions of the bands in the cyclopentanes and cyclohexanes are produced by differences in the skeletal structure. Eight cyclohexanes have been measured in the 3,200$\mathrm{cm}^{-1}$ region, and the positions of the two bands vary about $4 \mathrm{~cm}^{-1}$ or less from each other. This is almost within experimental error, which is about $2 \mathrm{~cm}^{-1}$. With higher resolution, no doubt, changes in their positions could be detected, but with a prism instrument it would not be feasible to use these bands as a method of distinguishing one cyclohexane from another.

Six cyclopentanes have been measured, and the values for the two $\mathrm{CH}_{2}$ vibrations fall at about 2,866 and $2,952 \mathrm{~cm}^{-1}$. There is little variation from these values by any of the compounds. Because of the presence of $\mathrm{CH}_{3}$ groups, there are other bands in the 3.4- $\mu$ region. In some cases the $\mathrm{CH}_{3}$ bands may fall on the side of the $\mathrm{CH}_{2}$ bands and cause' a slight change in their position. The $\mathrm{CH}_{2}$ vibrations in the cyclohexanes occur at longer wavelengths than in the cyclopentanes. The $\mathrm{CH}_{3}$ bands are not entirely overlapped in methylcyclohexane and can be observed at 2,952 and 2,872 $\mathrm{cm}^{-1}$.

In addition to $\mathrm{CH}, \mathrm{CH}_{2}$, and $\mathrm{CH}_{3}$ stretching vibrations, which occur in the $3.4-\mu$ region, there are combination bands that are located in this region. Twenty-seven bands have been observed in the spectrum of methylcyclohexane in the region from 2.25 to $4.50 \mu$. In the region of $3.4 \mu$ the intense bands probably mask low intensity bands. The classification of the bands in this region has been made by the use of the observed wavelengths of the methylcyclohexane spectrum [4]. The results are tabulated in table 3 . Several strong

TABLE 3. Combination bands in the near infrared of methylcyclohexane

\begin{tabular}{|c|c|c|c|}
\hline \multirow{2}{*}{ Term } & \multicolumn{2}{|c|}{ Wave number } & \multirow{2}{*}{$\begin{array}{c}\text { Wave } \\
\text { length } \\
\text { observed }\end{array}$} \\
\hline & Calculated & Observed & \\
\hline & $\mathrm{cm}^{-1}$ & $\mathrm{~cm}^{-1}$ & $\mu$ \\
\hline$\nu_{1}$ & . & 442 & 22.60 \\
\hline$\nu_{2}$ & . & 547 & 18. 29 \\
\hline$\nu_{3}$ & ...... & 607 & 16.48 \\
\hline$\nu_{4}$ & . . . & 843 & 11. 86 \\
\hline$\nu_{5}$ & $\ldots$ & 872 & 11. 47 \\
\hline$\nu_{6}$ & - n & 910 & 10.99 \\
\hline$\nu 7$ & ....... & 967 & 10.34 \\
\hline$\nu_{8}$ & ........ & 1,093 & 9.15 \\
\hline$\nu_{1}+\nu_{3}$ & 1,049 & 1,033 & 9. 68 \\
\hline$\nu_{9}$ & ...... & 1,167 & 8.57 \\
\hline$\nu_{10}$ & ....... & 1,248 & 8.01 \\
\hline$\nu_{1}+\nu_{4}$ & 1,285 & 1,263 & 7. 92 \\
\hline$\nu_{1}+\nu_{5}$ & 1,314 & 1,305 & 7. 66 \\
\hline$\nu_{1}+\nu_{6}$ & 1,352 & 1,346 & 7. 43 \\
\hline$\nu_{2}+\nu_{4}$ & 1,390 & 1,364 & 7. 33 \\
\hline$\nu_{11}$ & - . & 1,376 & 7. 27 \\
\hline$\nu_{12}$ & ........ & 1,458 & 6. 86 \\
\hline $2 \nu_{6}$ & 1,820 & 1,799 & 5. 56 \\
\hline$\nu_{1}+\nu_{11}$ & 1,818 & ........ & -.... \\
\hline$\nu_{2}+\nu_{11}$ & 1,923 & 1,901 & 5. 26 \\
\hline$\nu_{1}+\nu_{3}+\nu_{5}$ & 1,921 & ........ & ........ \\
\hline$\nu_{5}+\nu_{9}$ & 2,039 & 2,016 & 4. 96 \\
\hline$\nu_{7}+\nu_{9}$ & 2,134 & 2,123 & 4. 71 \\
\hline$\nu_{1}+\nu_{4}+\nu_{6}$ & 2,195 & 2,174 & 4. 60 \\
\hline$\nu_{6}+\nu_{11}$ & 2,286 & 2,268 & 4. 41 \\
\hline$\nu_{1}+\nu_{5}+\nu_{7}$ & 2,281 & _....... & - ...... \\
\hline$\nu_{7}+\nu_{12}$ & 2,425 & 2,398 & 4. 170 \\
\hline$\nu_{1}+\nu_{3} \nu_{11}$ & 2,425 & - n.... & - \\
\hline$\nu_{1}+\nu_{6}+\nu_{8}$ & 2,445 & 2,426 & 4. 122 \\
\hline $2 \nu_{10}$ & 2,496 & 2,483 & 4. 027 \\
\hline$\nu_{9}+\nu_{12}$ & 2,625 & 2,605 & 3. 839 \\
\hline$\nu_{10}+\nu_{11}$ & 2,624 & -...... & -...... \\
\hline$\nu_{4}+\nu_{5}+\nu_{7}$ & 2,682 & 2,667 & 3. 751 \\
\hline$\nu_{4}+\nu_{6}+7$ & 2,720 & 2,706 & 3. 696 \\
\hline $2 \nu_{11}$ & 2,752 & 2,726 & 3. 669 \\
\hline$\nu_{1}+\nu_{6}+\nu_{12}$ & 2,810 & 2,794 & 3. 579 \\
\hline$\nu_{13}$ & - & 2,854 & 3. 504 \\
\hline$\nu_{14}$ & ...... & 2,927 & 3.416 \\
\hline$\nu_{1}+2 \nu_{11}$ & 3,194 & 3,163 & 3. 162 \\
\hline$\nu_{1}+\nu_{13}$ & 3,296 & 3,271 & 3.057 \\
\hline$\nu_{2}+2 \nu_{11}$ & 3,299 & - ...... & ........ \\
\hline$\nu_{1}+\nu_{14}$ & 3,369 & 3,348 & 2. 987 \\
\hline$\nu_{2}+\nu_{14}$ & 3,474 & 3,464 & 2. 887 \\
\hline$\nu_{4}+\nu_{5}+\nu_{7}+\nu_{11}$ & 4,058 & 4,029 & 2. 483 \\
\hline$\nu_{9}+\nu_{14}$ & 4,094 & 4,075 & 2. 454 \\
\hline $2 \nu_{11}+\nu_{12}$ & 4,210 & 4,184 & 2. 390 \\
\hline$\nu_{11}+\nu_{14}$ & 4,303 & 4,279 & 2. 337 \\
\hline$\nu_{12}+\nu_{14}$ & 4,385 & 4,348 & 2. 300 \\
\hline
\end{tabular}


fundamental bands of methylcyclohexane, such as $\nu_{6}, \nu_{7}, \nu_{9}$, and $\nu_{11}$ were found to give combination wave numbers that agreed well with observed bands. In each case the experimental value was about $25 \mathrm{~cm}^{-1}$ less than the calculated value. Because of higher order terms, the combination bands occur at longer wavelengths than would be expected by considering the position of the band to be the sum of the wave numbers of two fundamental bands. By the use of several of the more intense bands, it was found that the calculated values would be in error by about $25 \mathrm{~cm}^{-1}$ because of neglecting the anharmonicity of the combination bands. In assigning the weaker bands the agreement was considered good when the calculated values were greater than the observed values by 15 to $35 \mathrm{~cm}^{-1}$.

The spectra of methylcyclopentane and ethylcyclopentane contain a number of bands in the 2 - to $4-\mu$ region, but the number is not as great as found for methylcyclohexane. Some of these bands have been classified, and the results are tabulated in tables 4 and 5 . The wave numbers of the fundamental bands are taken from previous measurements $[4,5]$. The long wavelength fundamental bands are not known, but they are usually of low intensity and do not produce strong bands in combination.

Two compounds, cyclohexene and cyclopentene, contain $\mathrm{CH}_{2}$ groups and have a skeletal structure similar to that of the cyclohexanes and cyclo-

TABLE 4. Combination bands in the near infrared of methylcyclopentane

\begin{tabular}{|c|c|c|c|c|c|c|c|}
\hline \multirow{2}{*}{ Term } & \multicolumn{2}{|c|}{$\begin{array}{c}\text { Wave } \\
\text { number }\end{array}$} & \multirow{2}{*}{$\begin{array}{l}\text { Wave- } \\
\text { length } \\
\text { ob- } \\
\text { serv- } \\
\text { ed }\end{array}$} & \multirow{2}{*}{ Term } & \multicolumn{2}{|c|}{$\begin{array}{c}\text { Wave } \\
\text { number }\end{array}$} & \multirow{2}{*}{$\begin{array}{c}\text { Wave- } \\
\text { length } \\
\text { ob- } \\
\text { serv- } \\
\text { ed }\end{array}$} \\
\hline & $\begin{array}{l}\text { Cal- } \\
\text { culat- } \\
\text { ed }\end{array}$ & $\begin{array}{l}\text { Ob- } \\
\text { serv- } \\
\text { ed }\end{array}$ & & & $\begin{array}{l}\text { Cal- } \\
\text { culat- } \\
\text { ed }\end{array}$ & $\begin{array}{c}\text { Ob- } \\
\text { serv- } \\
\text { ed }\end{array}$ & \\
\hline & $\mathrm{cm}^{-1}$ & $\mathrm{~cm}^{-1}$ & $\mu$ & & $\mathrm{cm}^{-1}$ & $\mathrm{~cm}^{-1}$ & $\mu$ \\
\hline$\nu_{1}$ & ... & 431 & 23. 22 & $2 \nu_{5}$ & 2,702 & 2,698 & 3. 707 \\
\hline $2 \nu_{1}$ & 862 & 842 & 11.87 & $2 \nu 6$ & 2,754 & 2,730 & 3.663 \\
\hline$\nu_{2}$ & $\ldots$ & 902 & 11.09 & $\nu_{4}+\nu_{7}$ & 2,753 & ... & $\ldots$. \\
\hline$\nu_{3}$ & -.. & 1,139 & 8.78 & $\nu_{8}$ & ... & 2,866 & 3.489 \\
\hline$\nu_{4}$ & -- & 1,295 & 7. 72 & $\nu_{9}$ & ... & 2,952 & 3. 387 \\
\hline$\nu_{5}$ & $\ldots$ & 1,351 & 7.40 & $\nu_{1}+\nu_{8}$ & 3,297 & 3,268 & 3. 060 \\
\hline$\nu_{6}$ & - - & 1,377 & 7. 26 & $\nu_{1}+\nu_{9}$ & 3,383 & 3,356 & 2. 979 \\
\hline$\nu 7$ & $\ldots$ & 1,458 & 6.86 & $\nu_{3}+\nu_{9}$ & 4, 091 & 4,075 & 2. 454 \\
\hline$\nu_{2}+\nu_{4}$ & 2,197 & 2,179 & 4. 59 & & & & \\
\hline & & & & $\nu_{4}+\nu_{8}$ & 4,161 & 4,139 & 2. 416 \\
\hline & & & & $\nu_{7}+\nu_{8}$ & 4,324 & 4,297 & 2. 327 \\
\hline$\nu_{3}+\nu_{5}$ & 2,490 & 2,457 & 4.070 & $\nu_{6}+\nu_{9}$ & 4,329 & ... & -.. \\
\hline$\nu_{4}+\nu_{5}$ & 2,646 & 2,627 & 3.807 & ....... & $\cdots$ & $\ldots$ & $\ldots$ \\
\hline
\end{tabular}

TABLE 5. Combination bands in the near infrared of ethylcyclopentane

\begin{tabular}{|c|c|c|c|c|c|c|c|}
\hline \multirow{2}{*}{ Term } & \multicolumn{2}{|c|}{$\begin{array}{c}\text { Wave } \\
\text { number }\end{array}$} & \multirow{2}{*}{$\begin{array}{l}\text { Wave- } \\
\text { length } \\
\text { ob- } \\
\text { serv- } \\
\text { ed }\end{array}$} & \multirow{2}{*}{ Term } & \multicolumn{2}{|c|}{$\begin{array}{c}\text { Wave } \\
\text { number }\end{array}$} & \multirow{2}{*}{$\begin{array}{c}\text { Wave- } \\
\text { length } \\
\text { ob- } \\
\text { serv- } \\
\text { ed }\end{array}$} \\
\hline & $\begin{array}{c}\text { Cal- } \\
\text { culat- } \\
\text { ed }\end{array}$ & $\begin{array}{c}\text { Ob- } \\
\text { serv- } \\
\text { ed }\end{array}$ & & & $\begin{array}{c}\text { Cal- } \\
\text { culat- } \\
\text { ed }\end{array}$ & $\begin{array}{c}\text { Ob- } \\
\text { serv- } \\
\text { ed }\end{array}$ & \\
\hline & $\mathrm{cm}^{-1}$ & $\mathrm{~cm}^{-1}$ & $\mu$ & & $\mathrm{cm}^{-1}$ & $\mathrm{~cm}^{-1}$ & $\mu$ \\
\hline$\nu_{1}$ & ... & 768 & 13.02 & $\nu_{5}+\nu_{7}$ & 2,667 & 2,647 & 3. 778 \\
\hline$\nu_{2}$ & ... & 931 & 10. 74 & $2 \nu_{7}$ & 2,666 & -.. & -. \\
\hline$\nu_{3}$ & $\ldots$ & 1,020 & 9.80 & $\nu_{5}+\nu_{9}$ & 2,750 & 2,736 & 3. 655 \\
\hline$\nu_{4}$ & $\ldots$ & 1,131 & 8. 84 & $2 \nu_{8}$ & 2,754 & -.. & ... \\
\hline$\nu_{5}$ & $\ldots$ & 1,290 & 7.75 & $\nu_{10}$ & ... & 2,866 & 3.489 \\
\hline$\nu_{6}$ & -.. & 1,313 & 7. 61 & $\nu_{11}$ & -.. & 2,956 & 3. 383 \\
\hline$\nu_{7}$ & -.. & 1,333 & 7. 50 & $\nu_{4}+\nu_{11}$ & 4,087 & 4,072 & 2. 456 \\
\hline$\nu 8$ & $\ldots$ & 1,377 & 7. 26 & $\nu_{5}+\nu_{10}$ & 4,156 & 4,129 & 2. 422 \\
\hline$\nu_{9}$ & ... & 1,460 & 6.85 & $\nu_{9}+\nu_{10}$ & 4. 326 & 4,290 & 2. 331 \\
\hline$\nu_{1}+\nu_{6}$ & 2,081 & 2,066 & 4. 84 & -.... - . & -.. & -.. & .... \\
\hline & & & & - & $\cdots$ & $\cdots$ & $\cdots$ \\
\hline$\nu_{2}+\nu_{6}$ & 2,244 & 2,227 & 4. 49 & -........ &.- & -.. & .... \\
\hline$\nu_{3}+\nu_{9}$ & 2,480 & 2,476 & 4. 038 & - & -.. &.-- & -.. \\
\hline $2 \nu_{6}$ & 2,626 & 2,621 & 3.816 & ....... & ... & ... & .... \\
\hline
\end{tabular}

pentanes respectively. The observed spectra show three strong bands with several weaker bands for each substance. In the spectrum of cyclohexene the band at $3,035 \mathrm{~cm}^{-1}$ arises from the $\mathrm{CH}$ vibration, and the corresponding vibration in cyclopentene is at $3,067 \mathrm{~cm}^{-1}$. The $\mathrm{CH}_{2}$ vibrations are somewhat modified by the $\mathrm{CC}$ double bond. The two bands are observed at 2,845 and $2,934 \mathrm{~cm}^{-1}$ in cyclohexene and 2,853 and $2,959 \mathrm{~cm}^{-1}$ in cyclopentene. The two components of the $\mathrm{CH}_{2}$ vibrations of cyclohexene are separated by $89 \mathrm{~cm}^{-1}$, and the separation is $73 \mathrm{~cm}^{-1}$ for the two bands in the cyclohexanes. The separation for the corresponding bands in cyclopentene and the cyclopentanes is 107 and $87 \mathrm{~cm}^{-1}$, respectively.

The position of the $\mathrm{CH}_{2}$ vibrations is dependent on the skeletal structure of the molecule. This can be seen more readily by comparing $\mathrm{CH}_{2}$ bands in other compounds that have different molecular structures. The compounds included in addition to those reported in this paper are formaldehyde [6] ketene [7, 8], cyclohexane [6], cyclopropane [6], and propylene [6]. The antisymmetrical vibration of the $\mathrm{CH}_{2}$ group, occurring when the two hydrogens are out of phase, has a larger wave number for all these compounds. In table 6 is given the value for the two $\mathrm{CH}_{2}$ bands of these substances and the difference in wave numbers between the two modes of vibration of each substance. From this table it is seen that the vibra- 
tions of the $\mathrm{CH}_{2}$ groups are not fixed values but vary with the type of the molecule.

In $n$-butylbenzene the three $\mathrm{CH}_{2}$ groups have bands at $3.42 \mu$ and $3.50 \mu$, which are close to the positions for the bands in $n$-butylcyclohexane. These two bands become of low intensity in the spectrum of sec-butylbenzene. The band at 3.30 $\mu$ is produced by the $\mathrm{CH}$ vibration of the benzene ring. This band checks closely in position with the $\mathrm{CH}$ band in cyclohexene.

TABLE 6. Location of $\mathrm{CH}_{2}$ vibrational bands for different types of molecules

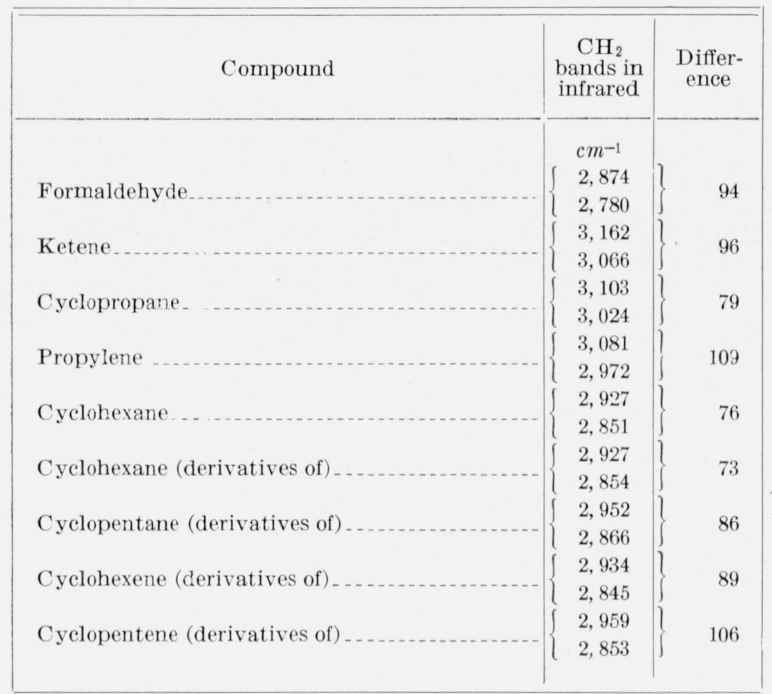

Many of these compounds that have been studied in the $3.4-\mu$ region have been measured previously in the region of 1.15 and $1.7 \mu$ by Lidell and Kasper [1] and by Rose [2]. The fundamental band and the harmonics should be related by the equation $\nu_{\mathrm{n}}=\nu_{0} n(1+n x)$, where $n$ is the number of the harmonic and $x$ is the anharmonic correction factor. It was found that considerable differences in the value of $\nu_{\mathrm{o}}$ and $x$, were obtained, depending on which two of the observed bands were used in the equation. The discrepancy in the constants was produced by experimental error in the observations. For an error of $0.01 \mu$ the wave number error would be $75 \mathrm{~cm}^{-1}$ at $1.15 \mu, 35 \mathrm{~cm}^{-1}$ at 1.70 $\mu$, and $9 \mathrm{~cm}^{-1}$ at $3.40 \mu$. Because the uncertainty of the wave numbers in the $3.4-\mu$ region is much smaller than in the 1.15 - and $1.7-\mu$ regions, and with the high resolution of $\mathrm{LiF}$ prism, this region is the best suited for the observation of the $\mathrm{CH}_{2}$ valence vibrations.

Fox and Martin [3] used a grating spectrometer, with good resolving power, to investigate a group of hydrocarbons in the $3.4-\mu$ region. Cyclopentene and some of the cyclohexanes were included in their work, and the positions of the bands observed by us check to $0.01 \mu$ or better with their values. The present work includes a wider region of the spectrum than that used by previous authors. For ten of the hydrocarbons, the region from 2 to $4 \mu$ has been included in order to show that many combination bands overlap the $3.4-\mu$ region. Consequently, the intensities of fundamental bands could not be used for quantitative determination of the number of $\mathrm{CH}, \mathrm{CH}_{2}$, and $\mathrm{CH}_{3}$ groups. By reducing the temperature of the samples, the band widths can be decreased and the chance of overlapping by combination bands becomes less likely. The cooling method offers some promise of providing a new technique for quantitative analysis in the region of the fundamental vibration.

In conclusion it should be pointed out that the region from 7 to $15 \mu$ is better suited for infrared analysis than the detailed study of the $3.4-\mu$ region. However, the measurement of the $\mathrm{CH}_{2}$ vibrations in different molecules reveals the presence of different force constants for the various types of skeletal structures.

\section{References}

[1] U. Liddel and C. Kasper, BS J. Research 11, 599 (1933) RP 610.

[2] F. W. Rose, Jr., J. Research NBS 19, 143 (1937) RP1017.

[3] J. J. Fox and A. E. Martin, Proc. Roy. Soc. (London) [A] 167, 257 (1938).

[4] E. K. Plyler, R. Stair, and C. J. Humphreys, J. Research NBS 38, 211 (1947).

[5] Infrared Spectrograms, No. 380, API Project, No. 44 (National Bureau of Standards).

[6] G. Herzberg, Infrared and Raman spectra of polyatomic molecules (D. Van Nostrand Co., Inc., New York, N. Y., 1945).

[7] F. Halverson and V. Z. Williams, J. Chem. Phys. 15, 552 (1947).

[8] W. R. Harp, Jr., and R. S. Rasmussen, J. Chem. Phys. 15, 778 (1947). 

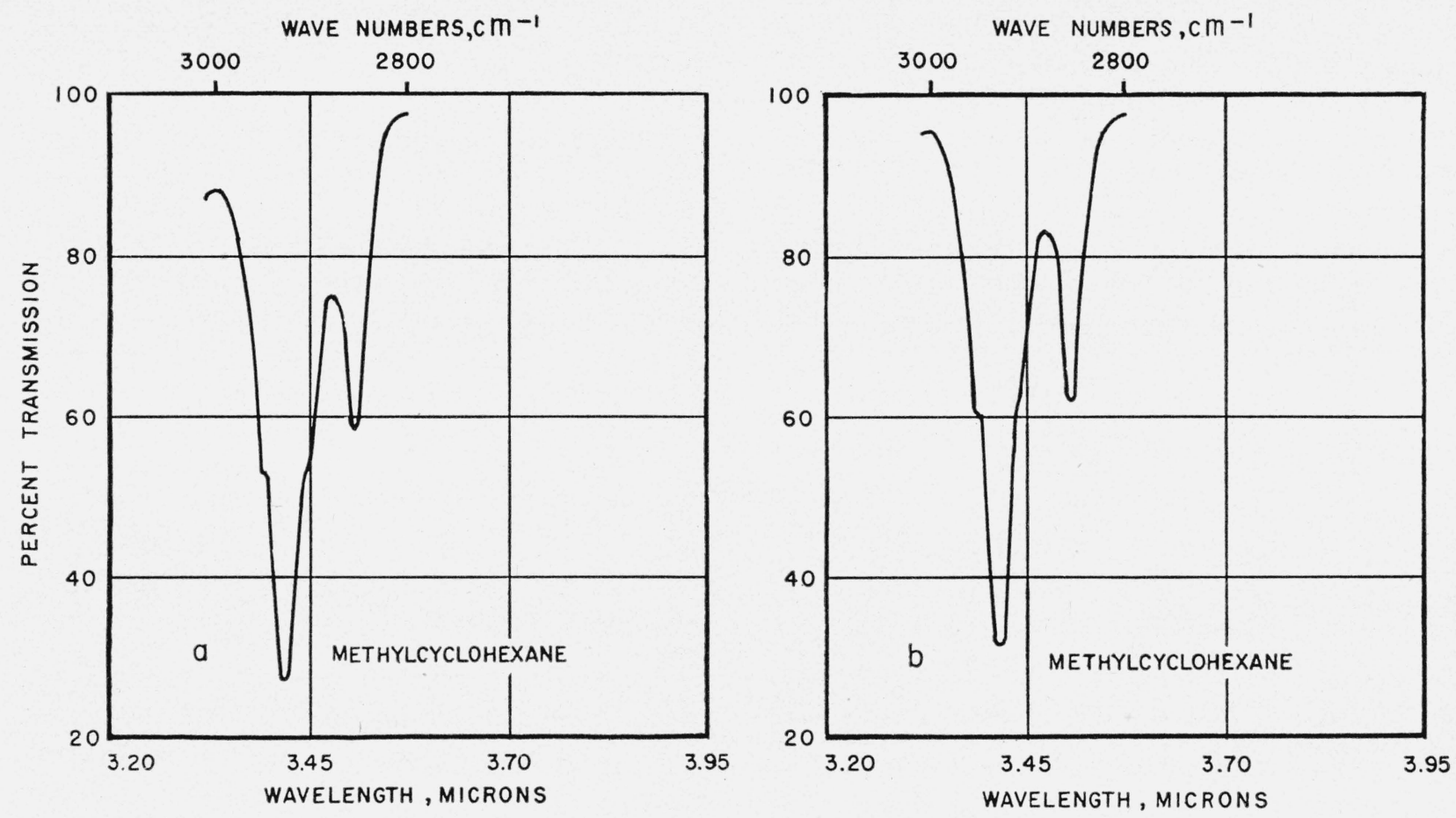

Figure 1. Infrared absorption in the 3.4- $\mu$ region

Curve a, Methylcyclohexane diluted in $\mathrm{CCl}_{4}$ with an equivalent cell thickness of $0.0017 \mathrm{~mm} ; \mathrm{b}$, the infrared absorption spectrum of methylcyclohexane for a liquid film on rock-salt windows.

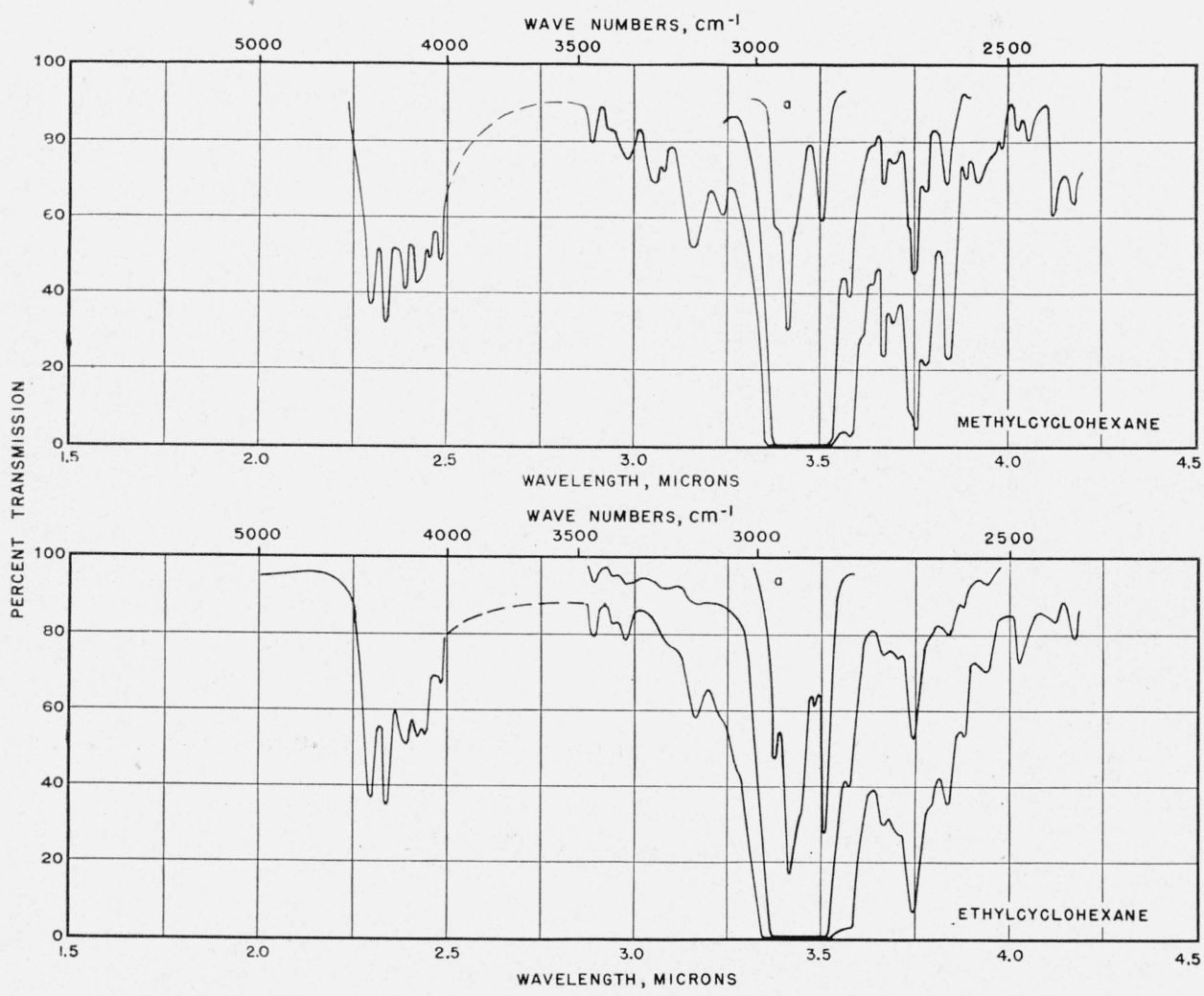

Figure 2. Infrared $a b-$ sorption spectra of methylcyclohexane and ethylcyclohexane from 2 to $4.2 \mu$.

The cell thicknesses for the liquids were 0.05 and $0.2 \mathrm{~mm}$. Insert (a) represents the spectra when the substance is diluted in $\mathrm{CCl}_{4}$. The equivalent cell thickness was $0.0017 \mathrm{~mm}$. 
Figure 3. Infrared $a b$ sorption spectra of cis1,2-dimethylcyclohexane and trans-1,2-dimethylcyclohexane.

The cell thicknesses are the same as those in figure 2 .

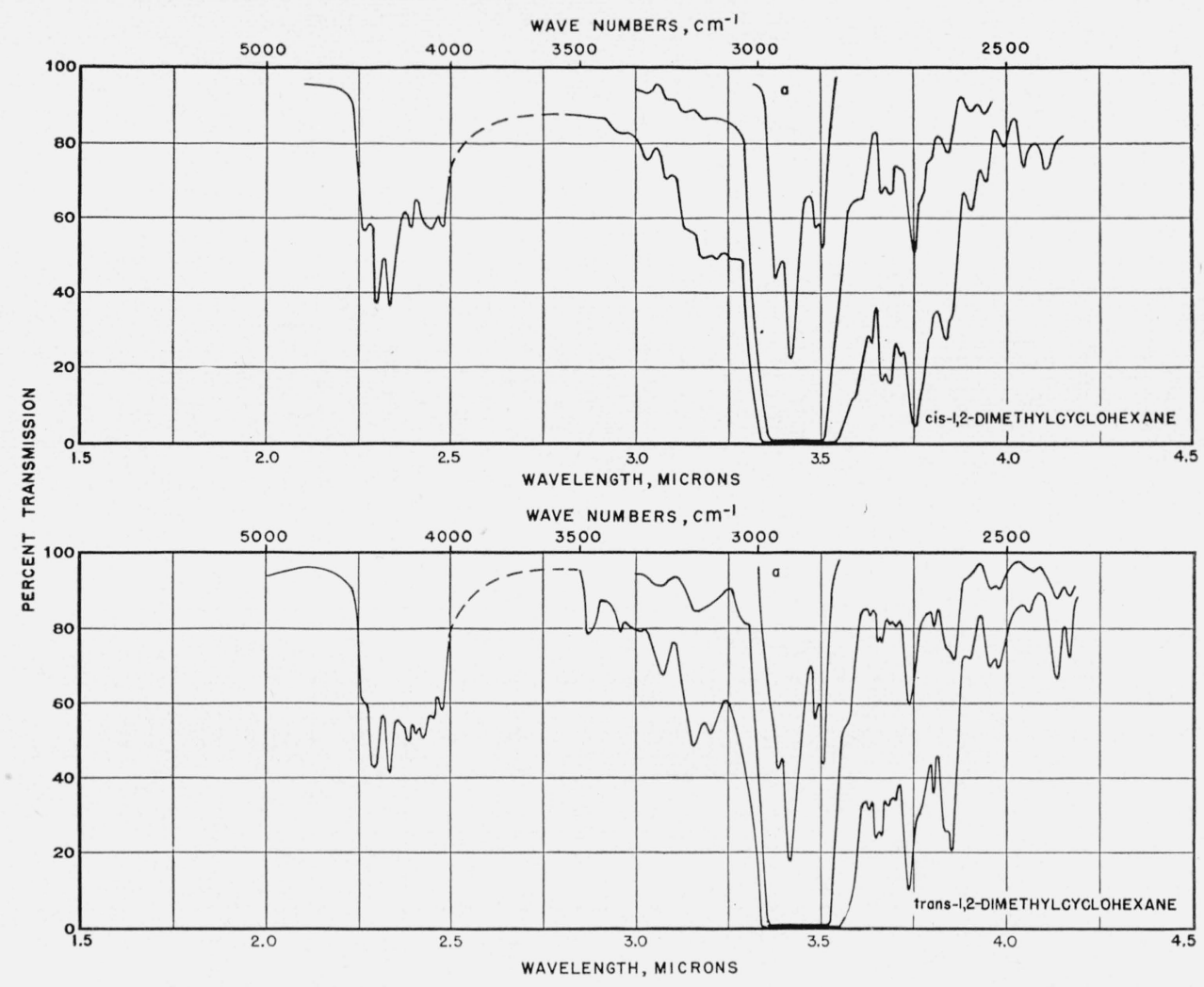

Figure 4. Infrared $a b$ sorption spectra of methylcyclopentane and ethylcyclopentane.

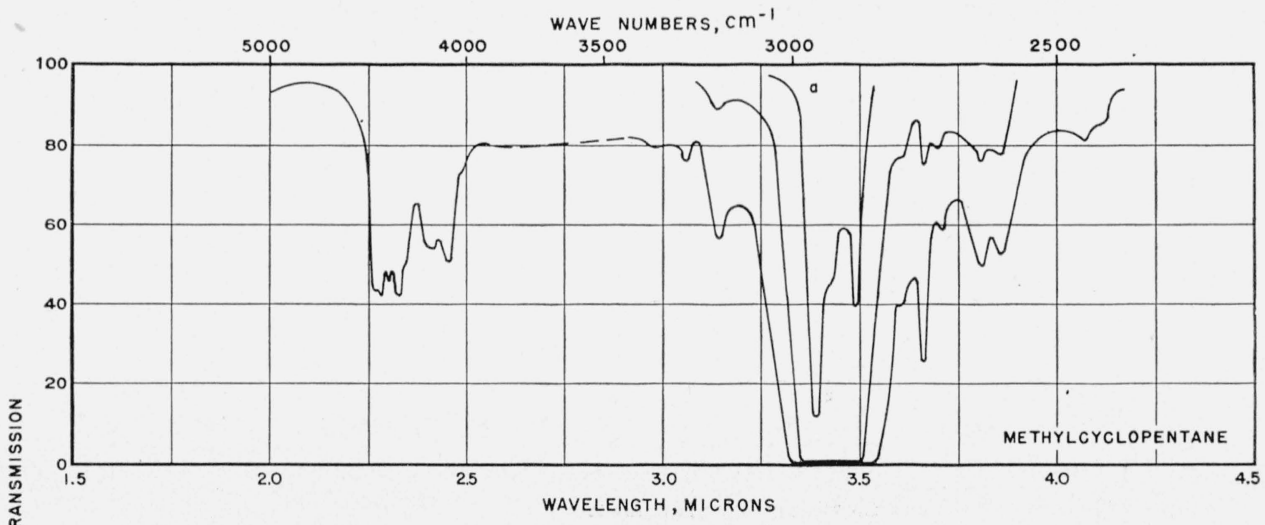

The cell thicknesses are the same as those in figure 2 .

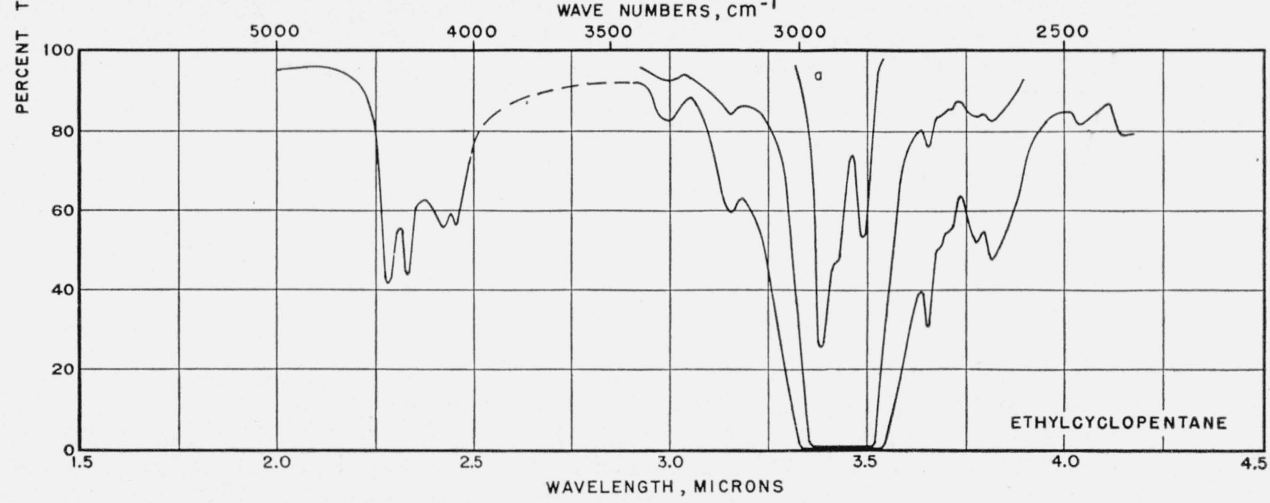




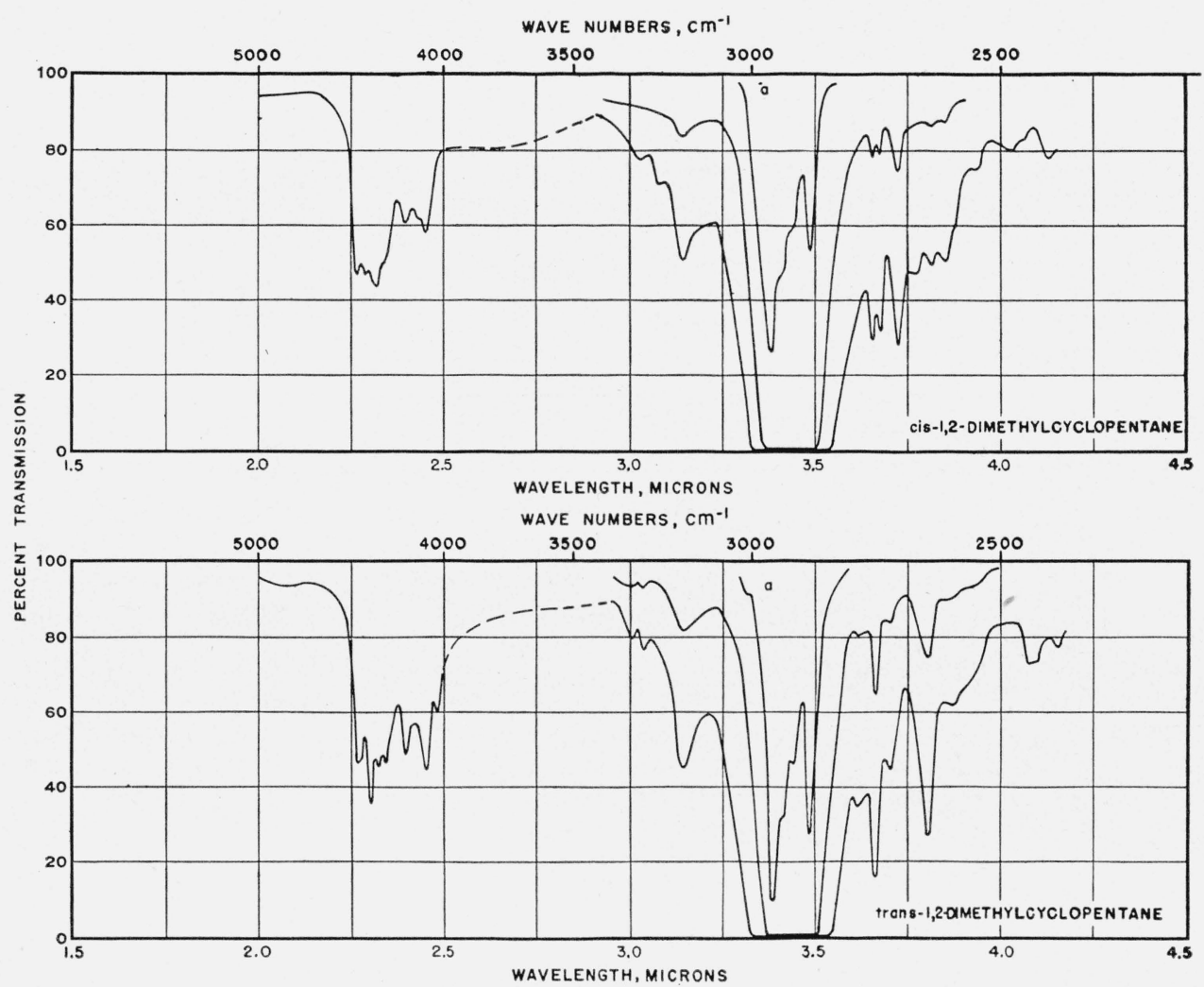

FiguRE 5. Infrared absorption spectra of cis- 1,2-dimethylcyclopentane and trans-1,2-dimethylcyclopentane. The cell thicknesses are the same as those in figure 2. 


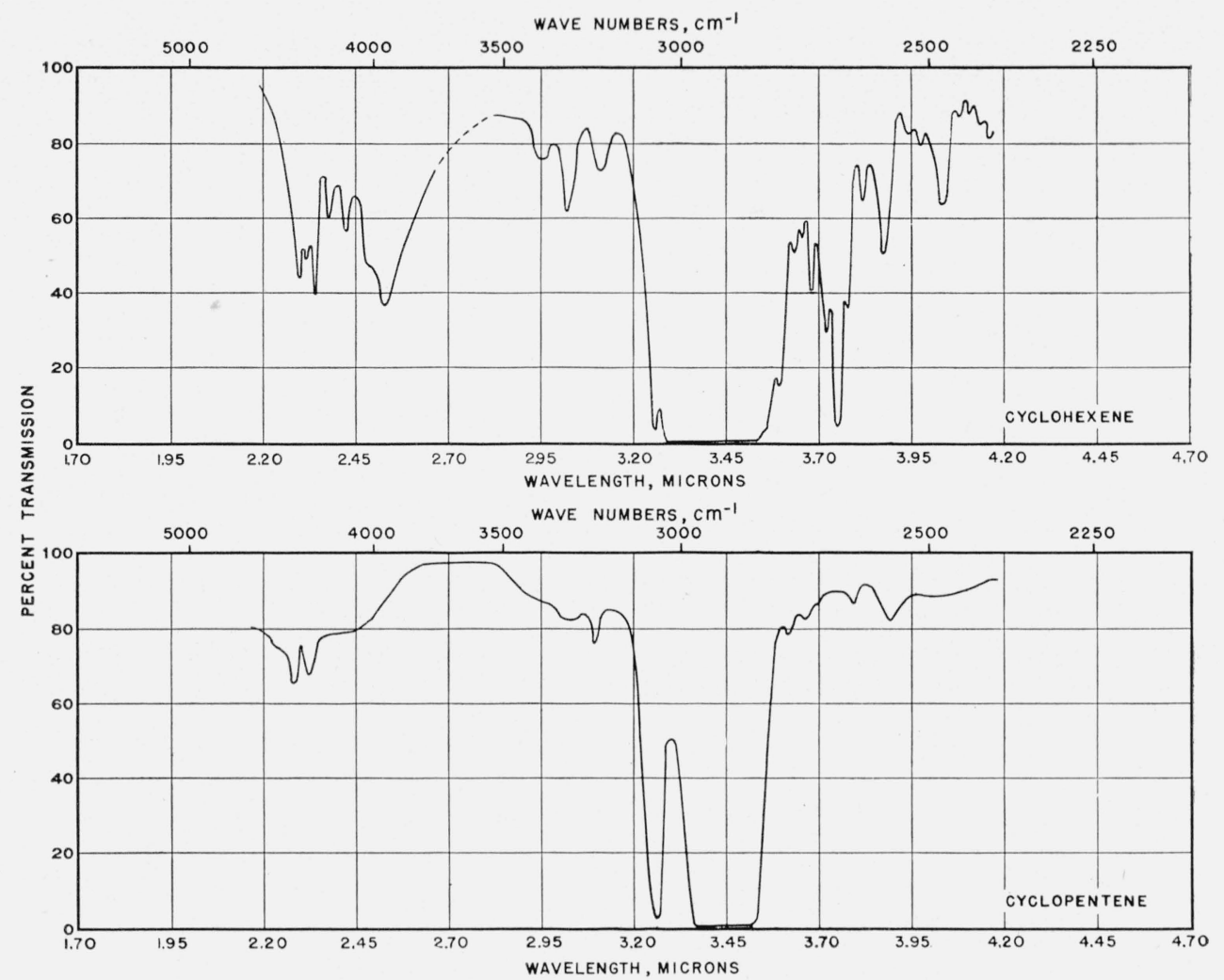

Figure 6. Infrared absorption spectra of cyclohexene and cyclopentene.

The cell thickness is $0.2 \mathrm{~mm}$ for cyclohexene and $0.05 \mathrm{~mm}$ for cyclopentene.

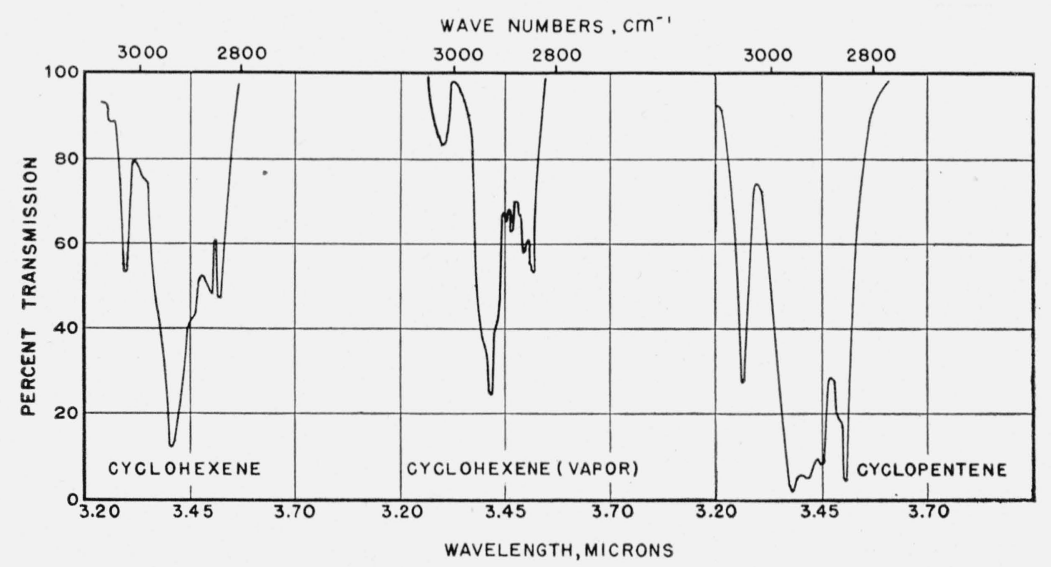

FIGURE 7. Infrared absorption spectra of cyclohexene, cyclohexene vapor, and cyclopentene in the region of $3.4 \mu$.

The two liquids were diluted in $\mathrm{CCl}_{4}$. The equivalent cell thickness was $0.0017 \mathrm{~mm}$. 


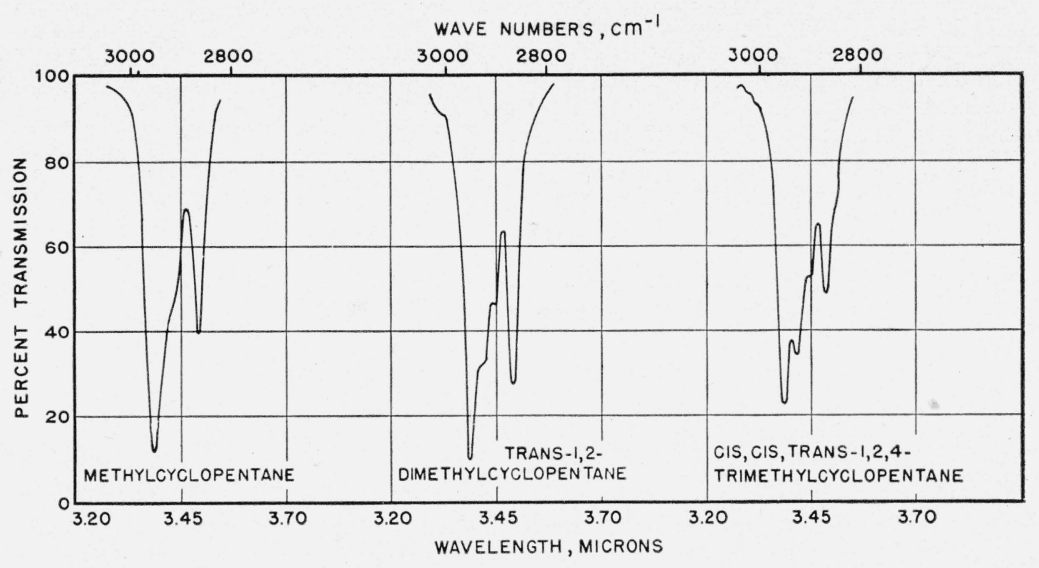

FIGURE 8. A comparison of the infrared absorption spectra of methycyclopentane, trans-1,2-dimethylcyclopentane, and cis, cis, trans-1,2,4-trimethylcyclopentane in the $3.4-\mu$ region.

All three liquids were diluted in $\mathrm{CCl}_{4}$, so that the equivalent cell thickness is $0.0017 \mathrm{~mm}$.

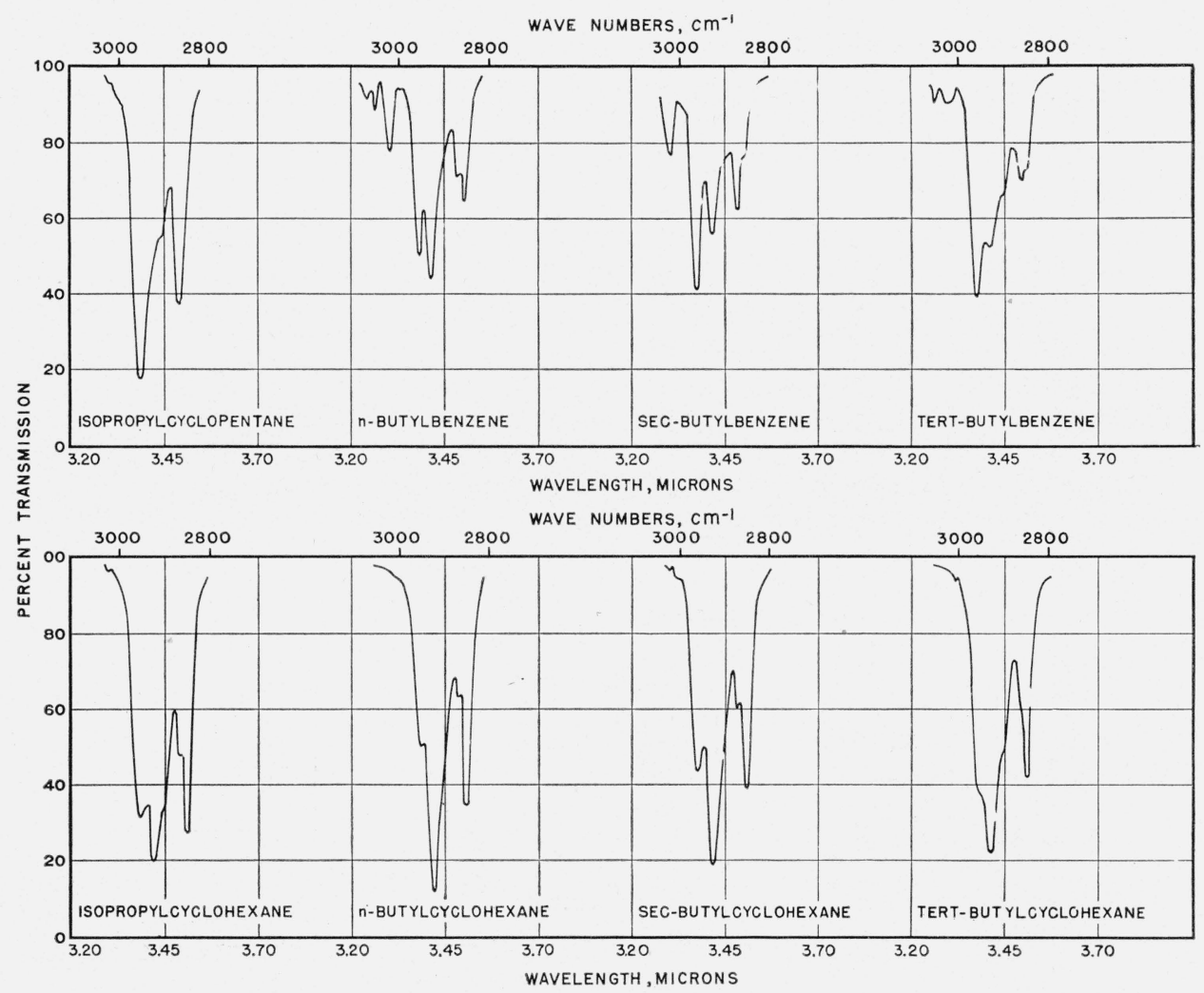

FIguRE 9. A comparison of the infrared absorption spectra of some derivatives of cyclopentane, cy clohexane, and benzene in the $3.4-\mu$ region.

All of the liquids were diluted in $\mathrm{CCl}_{4}$, so that the equivalent cell thickness is $0.0017 \mathrm{~mm}$.

Washington, February 16, 1949. 